\title{
OS SALÕES DE ARTE CONTEMPORÂNEA DE CAMPINAS
}

Renata Cristina de Oliveira Maia Zago (mestre IA/Unicamp)

Universidade Estadual de Campinas - Instituto de Artes

\section{Antecedentes das exposições de arte contemporânea em Campinas}

As origens do movimento de "renovação da arte" em Campinas surgem basicamente na atuação de alguns artistas que tinham o desejo comum de romper com os padrões acadêmicos estabelecidos na cidade. À medida que aumentava o acesso à arte contemporânea, e o acontecimento da I Bienal foi decisivo, os artistas sentiram necessidade de um trabalho mais consciente e começaram a buscar novas soluções plásticas.

Thomaz Perina, enquanto professor de uma escola de arte, começou a discutir sua teoria e seus métodos para ensinar. Suas idéias sobre a arte também não deixaram de influenciar alguns alunos, que assumiram a necessidade desse processo criativo questionador. Assim, Geraldo de Souza, Maria Helena Motta Paes e Francisco Biojone começam a colocar em dúvida suas paisagens, naturezas mortas e figuras.

Em 1957, Geraldo Jurgensen chega do Rio de Janeiro, onde terminara o curso de Arquitetura, trazendo novas experiências de exposições de arte contemporânea. Une-se então a Perina, seus amigos Mário Bueno e Enéas Dedecca e seus alunos e resolvem organizar uma exposição. Raul Porto comparece com alguns desenhos e são ainda convidados dois artistas italianos residentes em Campinas, Edoardo Belgrado e Franco Sacchi. Além de outros nomes: Geraldo Décourt (de São Paulo), Ermes de Bernardi, Mário Carneiro (do Rio) e Lélio Coluccini.

Isso deu então origem, em 04 de setembro de 1957, à I Exposição de Arte Contemporânea de Campinas, no saguão do Teatro Municipal. Assim, o espaço anteriormente reservado apenas para a arte tradicional começou a ceder lugar à arte nova.

Após a exposição, os artistas passaram a se reunir e iniciaram então, a luta por um objetivo: criar a consciência da arte contemporânea na cidade de Campinas. Se autodenominaram Grupo Vanguarda ${ }^{1}$ e passaram a

1 O Grupo Vanguarda contou de forma definitiva e constante com os seguintes artistas: Thomaz Perina, Mário Bueno, Geraldo Jurguensen, Enéas Dedeca, Francisco Biojone, Franco Sacchi, Geraldo de Souza, Maria Helena Motta Paes Raul Porto. Integrou-se em 1964 Bernardo Caro. Edoardo 
organizar a II Exposição de Arte Contemporânea de Campinas. Com a participação do jornalista e poeta Alberto Amêndola Heinzl, redigem um manifesto, contendo os objetivos, princípios e estratégias do grupo. Este foi publicado no Jornal do Centro de Ciências, Letras e Artes de Campinas, em junho de 1958.

O objetivo do grupo era uma união de artistas para realizarem exposições, diferente, por exemplo, dos grupos Ruptura e Frente, em que os artistas seguiam uma linha ou um pensamento em comum, dentro do grupo. Nada havia em comum nas obras dos artistas do Vanguarda, apenas uma vontade de mostrar a Campinas uma nova maneira de expressão, uma nova tendência.

Essa vontade dos artistas campineiros de mostrar sua arte tornouse uma necessidade ainda maior e um problema quando o Teatro Municipal da cidade foi fechado por período indeterminado. A galeria Aremar, pertencente a Raul Porto, era o único local em que o grupo ainda podia expor. Dessa forma, criar um local para exposições permanentes de arte contemporânea tornou-se o maior objetivo do grupo.

Observar o que ocorria no panorama artístico de São Paulo, como os acontecimentos periódicos das Bienais, como já destacamos, e a fundação do Museu de Arte Contemporânea da Universidade de São Paulo, em 1963, foram fatores decisivos para que a Secretária da Educação e Cultura, na época Jacy Milani, apoiasse a idéia defendida pelo grupo Vanguarda: a criação de um museu.

Assim, em setembro de 1965, a prefeitura municipal criou o Museu de Arte Contemporânea de Campinas - José Pancetti (MACC) na Avenida da Saudade junto à Secretaria Municipal de Cultura. Somente após alguns anos, em 1976, o MACC recebeu um prédio que seria sua sede definitiva, onde se encontra atualmente, na Avenida Benjamin Constant, 1633.

Para sua constituição tinham sido ouvidos diversos artistas da cidade, incluindo os acadêmicos. Ponderações dos artistas do Vanguarda foram decisivas quando Jacy Milani decidiu que seria um museu de arte contemporânea. Garantida sua implantação, tratou-se de realizar

Belgrado, Geraldo Dècourt, Ermes de Bernardi, membros fundadores, participaram - por diferentes motivos - de duas ou três exposições. Belgrado afastou-se de Campinas em virtude de trabalho, retornando depois à Itália. José Armando Pereira da Silva e Alberto Amêndola Heinzl, críticos de arte, participaram do grupo por diversos anos contribuindo principalmente com a divulgação através da página Minarete, do jornal de Campinas Correio Popular. 
imediatamente a sua inauguração com o I Salão de Arte Contemporânea de Campinas.

No momento em que o MACC assume as atividades das artes plásticas locais, parece que, o grupo Vanguarda espontaneamente como surgiu, começa a se dispersar. Seus artistas, independentes continuam a participar de mostras, salões e bienais.

\section{Salões de Arte Contemporânea de Campinas: Um Panorama}

Os Salões de Arte Contemporânea de Campinas (SACCs) aconteceram, quase todos os anos, de 1965 a 1977, com uma retomada nos anos 1980, quando foram realizadas duas mostras. $\mathrm{O}$ enfoque desta pesquisa são os Salões que aconteceram nas décadas de 1960 e 70, pois as edições dos anos 1980 não tiveram o mesmo caráter das anteriores.

O I Salão de Arte Contemporânea de Campinas ocorreu concomitante à criação do Museu de Arte Contemporânea de Campinas "José Pancetti" e a sua realização, bem como dos conseguintes salões, teve como objetivo iniciar o acervo do museu recém fundado.

Inicialmente realizados nos mesmos moldes de um salão tradicional, os SACCs foram, ao longo de suas realizações, modificando seu caráter e sua estrutura e chegaram a destacar-se em âmbito nacional, principalmente nos anos de 1974 e 75.

No decorrer desta pesquisa percebemos a grande importância dos SACCs e, dessa maneira podemos destacar seu caráter inovador para o interior do Estado de São Paulo, já que no eixo Rio - São Paulo já aconteciam importantes mostras ou eventos como as Jovem Arte Contemporânea (JAC) do Museu de Arte Contemporânea da Universidade de São Paulo, os Panoramas do Museu de Arte Moderna de São Paulo e os Domingos de Criação no aterro do Flamengo (anos 1970 - Museu de Arte Moderna do Rio de Janeiro), entre outras. Podemos citar outras mostras de destaque em grandes centros no mesmo período, como os Salões de Arte Moderna de Brasília, a Bienal da Bahia e o Salão da Bússola.

Porém, no caso das JACs e dos Domingos de Criação, temos duas pessoas fundamentais envolvidas na realização dos eventos: Walter Zanini e Frederico Morais respectivamente, o que não aconteceu nos Salões de Campinas, que eram promovidos pela Secretaria de Educação e Cultura, ou seja, apesar da participação de um júri competente, era uma mostra instituída pela prefeitura da cidade. 
O que nos faz comparar os SACCs às citadas exposições é o fato de não pertencerem ao circuito das grandes mostras instituídas como as Bienais Internacionais de São Paulo ou os Salões de Arte Moderna do Rio de Janeiro e, ainda, percebemos a participação dos mesmos artistas fundamentais e a revelação de outros.

Os SACCs, que no início obtiveram pequeno destaque, aos poucos transformaram-se em acontecimentos de grande relevância, procurados por artistas do Brasil todo, não apenas aqueles que buscavam um reconhecimento, mas também por nomes de prestígio nas artes plásticas dos anos 1970, como Evandro Carlos Jardim, Mira Schendel, Antonio Henrique Amaral, entre outros.

Porém, em recente entrevista, a crítica de arte e historiadora Aracy Amaral traz à luz um importante dado: “(...) a participação desses artistas não se deve apenas à relevância do evento, mas ao fato de que em inúmeras edições foram oferecidos prêmios em dinheiro aos primeiros colocados. Isso era uma prática freqüente de instituições, o que fazia com que esses artistas enviassem seus trabalhos a Salões no Brasil inteiro."2

Todavia, o que nos permite afirmar com segurança que os SACCs consistiam em mostras nacionalmente reconhecidas, é o grande número de inscrições de artistas encontradas na documentação histórica do MACC, provenientes dos mais diversos locais do país, que aumentavam substancialmente a cada ano.

Para cada mostra era formada uma comissão julgadora que selecionava e premiava os artistas. Os componentes dos júris dos SACCs, em sua maioria, eram críticos de arte e artistas de importante renome. A princípio os jurados eram responsáveis apenas pela seleção e premiação das obras, mas, a partir de 1971, começaram a discutir também a estrutura da exposição, o que acarretou, em 1974, 75 e 77, a total responsabilidade destes pela organização completa da mostra, desde sua idealização até a distribuição das obras pelo espaço expositivo.

A formação do júri modificou ainda a maneira como era realizada a premiação nos Salões. O número de artistas premiados diminuiu substancialmente no decorrer das realizações dos SACCs. Houve uma grande quantidade de artistas premiados nas primeiras mostras, além da atribuição de muitos prêmios por meio de empresas privadas, o que desapareceu definitivamente no V SACC (1969). Outra característica que

\footnotetext{
${ }^{2}$ Entrevista realizada pela autora no dia 14/02/2007.
} 
diferenciou o citado salão foi o fim da distribuição de prêmios de caráter consagratório (prêmios honoríficos - medalhas de ouro, prata e bronze).

Ainda na mesma edição da mostra, os membros do júri, além de procurar levar ao público a arte mais atual daquela época, já pretendiam discutir como deveria ser realizado um Salão de Arte. Esse debate iniciou-se ao serem abolidas as divisões por categorias tradicionais da arte (desenho, gravura, pintura, escultura). Na apresentação do catálogo, Aracy Amaral levanta uma questão pertinente: qual o objetivo da realização de um salão, mais especificamente deste salão, no determinado período e na cidade de Campinas.

Esta preocupação, na tentativa de ser atual, prolongou-se então até a última mostra. Porém, mostrou-se mais efetiva nos SACCs de 1971, 74 e 75. Primeiro, em 1971, no VII SACC, a comissão julgadora do certame de então - formada por Frederico Moraes, José Roberto Teixeira Leite, Mário Barata, Márcio Sampaio, Waldemar Cordeiro e Wolfgang Pheiffer - se reuniu após sua tarefa para debater a exposição, tal como ela ali se encontrava.

Márcio Sampaio, no Suplemento Literário ${ }^{3}$, afirma que os críticos chegaram a conclusões bastante interessantes e atuais. De acordo com documentos resgatados no arquivo do MACC, em resumo, foi sugerido que a Prefeitura de Campinas, pelo Departamento de Cultura, incumbiria o Museu de Arte Contemporânea de promover manifestações de Artes Visuais, durante os meses de setembro e outubro e com seis meses de preparação; essas manifestações seriam desenvolvidas em quatro setores, sob a direção de quatro comissários especialmente nomeados; cada comissário teria a liberdade de conceber e estruturar a forma de manifestação de seu setor, a qual seria precedida de um diagnóstico crítico e seguida de debates conclusivos; a cada comissário competiria, basicamente, formular o tema da manifestação em seu setor (podendo esse tema ser da atualidade ou retrospectivo) fazer convites nacionais que lhe parecessem convenientes e possíveis, dentro dos meios que lhe fossem fornecidos, selecionar, da maneira que melhor lhe aprouvesse, as obras que lhe fossem enviadas espontaneamente, e escolher os canais de divulgação e os locais de realização que lhe parecessem mais adequados ao tema escolhido; e a última etapa seria um seminário geral e interdisciplinar, com a participação de artistas, críticos, representantes das Universidades locais e de outras

\footnotetext{
3 Suplemento Literário, Belo Horizonte, 9 de outubro de 1971, p.4.
} 
entidades culturais e artísticas e do público interessado; e, finalmente os resultados finais da manifestação seriam publicados em monografia.

As direções por que se enveredou a Arte Visual Brasileira, a importância que teve esta mostra neste contexto e a sua condição de sétimo Salão, o que deu ao museu que o promoveu uma experiência já considerável e um papel cultural artisticamente importante no setor da criatividade nacional (inclusive porque reunia trabalhos de praticamente todo o país) foram razões que determinaram que a Secretaria de Educação e Cultura da Prefeitura de Campinas sugerisse promover um debate entre os membros do júri, propondo-lhes a apresentação dessas sugestões que visavam a uma reformulação pertinente e eficaz da idéia e do fato dos Salões de Arte, no sentido de uma maior 'utilidade' artística e cultural, com relação aos artistas e ao público. Mas as decisões do júri não foram retomadas no próximo ano.

Portanto, das soluções propostas pelo júri de 1971, chegou-se finalmente, em 1974, a sua primeira tentativa mais radical de atualização, quando o júri do momento decidiu fazê-la girar em torno de um tema e dividir a mostra entre artistas selecionados e artistas convidados, com o objetivo de trazer a Campinas diversos artistas de renome. Segundo Roberto Pontual, que integrou a comissão organizadora da mostra, o SACC foi reajustado em seus propósitos e regulamentos, através da proposta de uma comissão formada por ele, Márcio Sampaio e Olívio Tavares de Araújo ${ }^{4}$.

E assim nasceu o IX Salão de Arte Contemporânea de Campinas Desenho Brasileiro 74, visto não apenas na cidade de origem, mas também no Rio de Janeiro e em Brasília. Além disso, podemos ainda destacar o caráter de abertura permanente que a realização deste Salão pretendia instaurar. " $O$ que fizemos foi apenas uma proposta para esse ano", salienta Roberto Pontual. "E em nossa justificativa está explicito que, nos próximos salões, outras comissões, em função de seus momentos específicos, deverão apresentar outros projetos, mantendo o salão rigorosamente em dia com a arte". ${ }^{5}$

Assim, para a edição de 1975, o Salão abriu-se ainda mais radicalmente modificado. Se, em 1974, houvera a intenção de equilibrar o sistema tradicional do concurso com a necessidade de contar com artistas

\footnotetext{
${ }^{4}$ Folha de São Paulo, São Paulo, 27 de outubro de 1974.

${ }^{5}$ V eja, São Paulo, 30 de outubro de 1974, p.27.
} 
significativos através do convite direto, no X SACC - Arte no Brasil: Documento/ Debate, eliminou-se por completo o primeiro modo.

A comissão julgadora, formada por Aracy Amaral, Frederico Moraes e Aline Figueiredo, voltou-se apenas para o princípio do convite, escolhendo doze artistas brasileiros "com obra em plena maturidade, obras que se caracterizassem pela atualidade no nosso contexto, uma abrangência em termos territoriais assim como a diversidade das tendências vigentes". Os artistas convidados foram Mira Schendell, Rubem Valentim, Sérgio Camargo, João Câmara, Tomie Otake, Mário Bueno, Antonio Henrique Amaral, Franz Weissman, Amilcar de Castro, Humberto Espíndola, Nelson Leirner e Maria Leontina.

No entanto, o dado mais radical e importante deste Salão é que dele foi eliminada a presença direta, ou seja, física da obra. Ao invés de comparecer com duas ou três obras, cada artista encarregou-se de preparar uma documentação visual, em slides, capaz de indicar suas pretensões e os caminhos percorridos para pô-las em prática. Acompanhando a documentação visual, um texto depoimento, publicado em catálogo transferiu ao público o conhecimento da maneira pela qual o artista encara sua própria evolução, no contexto que o caracteriza. Durante três dias, 07, 08 e 09 de novembro de 1975, os doze artistas convidados debateram com o público suas obras mostradas em quarenta slides. Essa intensa vivência entre o público e os artistas, por três dias e entre os próprios convidados, é um fato importante para seu crescimento artístico.

Citando o crítico Roberto Pontual "não é preciso dizer mais nada para comprovar a oportunidade e a utilidade de uma exposição como esta, que se mostrou suficientemente capaz de ousadia, com vistas a manter um minimo de substância justificadora". 7

Como o Salão anterior, este teve uma grande importância e uma enorme divulgação, visto que existem críticas em inúmeros jornais e periódicos da época e, ademais, ele não permaneceu em Campinas, viajando para o Rio de Janeiro - $\boldsymbol{X} \boldsymbol{S A C C}$ no $\boldsymbol{M A M}$ (de 15 de janeiro a 8 de fevereiro de 1976) com debates nos dias 17 e 18 de janeiro com os artistas e os críticos de arte, São Paulo - X SACC na Pinacoteca do Estado (de 16 a 30 de março de 1976), com debates nos dias 19, 20 e 21 de março e Brasília - X SACC em Brasília - Fundação Cultural do Distrito

\footnotetext{
${ }^{6}$ Catálogo do X Salão de Arte Contemporânea de Campinas.

${ }^{7}$ Jornal do Brasil, Rio de Janeiro, 15 de janeiro de 1976.
} 
Federal (de 04 a 16 de abril de 1976), com debates nos dias 14, 15 e 16 de abril.

Dessa maneira, os Salões de Arte Contemporânea de Campinas aconteceram quase periodicamente todos os anos até 1977, adquirindo grande importância no decorrer dos anos. Segundo o historiador e crítico de arte José Roberto Teixeira Leite, jurado do VI e VII Salões, os SACCs eram considerados laboratórios para as Bienais de São Paulo ${ }^{8}$.

${ }^{8}$ Catálogo do VI Salão de Arte Contemporânea de Campinas. 